\title{
Formação para o Apoio Matricial: percepção dos profissionais sobre processos de formação
}

| ${ }^{1}$ Mônica Martins de Oliveira, ${ }^{2}$ Gastão Wagner de Sousa Campos |

Resumo: O artigo tem como objetivo principal analisar a percepção dos profissionais acerca de processos de formação que os auxiliem na realização do apoio matricial. A pesquisa ocorreu em Campinas (SP). Foram realizados dois movimentos investigativos: etapa exploratória (quantitativa) com 206 profissionais e pesquisa qualitativa, utilizando a técnica de grupo focal, com uma amostra intencional. Os participantes destacaram sua insatisfação com a ausência de formação sistemática para o apoio e a associaram ao escasso investimento que tem sido feito no Apoio Matricial no município. Eles percebem que a formação poderia ajudá-los a aprimorar o trabalho interdisciplinar e o cuidado ofertado, desde que o modelo pedagógico privilegie a reflexão sobre a prática.

> Palavras-chave: formação e desenvolvimento; apoio matricial; educação permanente em saúde.

\author{
1 Faculdade de Ciências \\ Médicas, Universidade Estadual \\ de Campinas. Campinas-SP, \\ Brasil (oliveira.moniquinha@ \\ gmail.com). \\ 2 Faculdade de Ciências \\ Médicas, Universidade Estadual \\ de Campinas. Campinas-SP, \\ Brasil (gastaowagner@mpc. \\ com.br).
}


O Apoio Matricial é um arranjo organizacional e, ao mesmo tempo, uma metodologia de trabalho, baseado no Método da Roda (CAMPOS, 2000). Nele, profissionais com profissões e especialidades diferentes daquelas das equipes apoiadas asseguram retaguarda especializada mediante suporte assistencial e técnico-pedagógico (CUNHA; CAMPOS, 2010; CUNHA; CAMPOS, 2011; CAMPOS; DOMITTI, 2007).

A metodologia do Apoio Matricial foi desenvolvida na rede de saúde em Campinas/SP a partir do final da década de 80. Objetivava-se tanto democratizar as relações de trabalho quanto qualificar o atendimento em saúde. Em 2008, foi incorporada à proposta ministerial de criação dos Núcleos de Apoio à Saúde da Família (NASF) como forma de ampliar a resolubilidade do trabalho das equipes de atenção básica (de Estratégia Saúde da Família) em todo o país (BRASIL, 2008). Com isso, o tema do Apoio Matricial se expandiu para muito além dos limites municipais de Campinas. No início de 2015, já contávamos com 3.925 equipes NASF implantadas, em suas três modalidades (BRASIL, 2015).

As diretrizes para a formação dos trabalhadores que desenvolvem ações de Apoio Matricial estão em processo de construção. Contudo, considera-se importante que tenham uma formação que os capacite em temas específicos ao seu núcleo de saber e ainda em habilidades de manejo de grupos, elaboração de ações no território a partir da análise das necessidades e discussão de casos na perspectiva interdisciplinar, considerando a abordagem familiar (CUNHA, 2009; OLIVEIRA, 2010; FIGUEIREDO, 2012; FURLAN, 2012).

Essas recomendações se estendem a todos os trabalhadores da saúde, especialmente àqueles inseridos na Atenção Básica. Em todos os casos, é preciso sempre pensar na formação enquanto processo, não de formatação, mas de refinamento técnico e de construção de habilidades humanísticas e éticas, como propõe Oury (1991).

Sendo assim, faz sentido falarmos em itinerário formativo para reforçar sua dimensão processual e contínua, inacabável (OURY, 1991). Esse tipo de compreensão atribui amplitude aos processos de formação, que passam a envolver tanto cursos formais, como graduação e pós-graduação - lato ou stricto sensu - como demais dispositivos e arranjos voltados para a discussão de 
problemas cotidianos, reflexão sobre a prática e desenvolvimento da postura profissional mediante aquisição ou aperfeiçoamento de habilidades e saberes. Em outras palavras, abrange as dimensões da educação continuada e da educação permanente descritas por Mancia, Cabral e Koerich (2004), Peduzzi et al. (2009) e Brasil (2009).

Aproximando-se da linha da educação permanente, Cunha e Dantas (2010) acreditam que a formação dos profissionais da saúde, incluindo a do Apoio Matricial, deve estar atrelada à prática. Contudo, ressaltam o caráter dialético entre reflexão e ação e valorizam a inclusão dos aspectos subjetivos e dos afetos produzidos no ambiente de trabalho. Assim, propõem garantir o que chamam de formação em serviço, que qualificaria as práticas em saúde.

Na mesma tendência, Campos, Cunha e Figueiredo (2013) e Figueiredo (2012) explicam que o Método Paideia para formação em saúde tem sido utilizado em diferentes instâncias de ensino, na graduação e em cursos de especialização, e que também pode ser empregado na formação de profissionais que desenvolvem Apoio Matricial. Esse modelo de formação incorpora elementos propostos para os grupos Balint-Paideia e trabalha combinando discussão de casos, reflexão sobre as práticas e ofertas teóricas. Aposta na possibilidade de que os profissionais alterem sua capacidade de análise e de cogestão de si mesmos e do mundo que os cerca.

Frente à complexidade do tema exposto e tendo em vista o histórico de Campinas no trabalho com o Apoio Matricial, precursor do NASF, acreditamos que a análise dos processos de formação e da experiência acumulada pelos seus trabalhadores nessa área poderá contribuir com a construção de uma política de pessoal voltada aos apoiadores matriciais de outros municípios.

Esta pesquisa teve como objetivo principal analisar a percepção dos profissionais acerca de processos de formação que os auxiliem na realização do Apoio Matricial. Como objetivos específicos, listamos: identificar os processos de formação a que os trabalhadores que desenvolvem Apoio Matricial tiveram acesso em sua trajetória profissional; compreender a percepção desses trabalhadores sobre a relevância de processos formativos para sua prática de apoio; investigar qual seria a formação desejável para o Apoio Matricial, segundo a opinião dos profissionais que desempenham essa função. 


\section{Metodologia}

Os resultados aqui apresentados partem de uma pesquisa de mestrado, financiada pela CAPES, dentro do Programa de Pós-Graduação em Saúde Coletiva da Universidade Estadual de Campinas, e integra uma pesquisa do Departamento de Saúde Coletiva, intitulada "Avaliação do Método de Apoio Paideia como estratégia de Educação Permanente para profissionais do SUS", financiada pelo CNPq.

Para o seu desenvolvimento, foram realizados dois movimentos investigativos: I) etapa exploratória (quantitativa) para conhecer o universo da pesquisa e II) pesquisa qualitativa com amostra intencional. Essa configuração baseou-se na metodologia de métodos mistos, proposta por Creswell (2007; 2009), por meio da estratégia explanatória sequencial. Nessa estratégia, emprega-se o método quantitativo para identificar questôes e temas a serem, posteriormente, analisados de modo mais aprofundado com o método qualitativo. Na presente pesquisa, a etapa exploratória (quantitativa) foi usada também para subsidiar a identificação de informantes-chave para a composição da amostra para a investigação qualitativa.

Houve aplicação de questionários a todos os profissionais do Apoio Matricial do SUS/Campinas para descrever o campo de maneira mais geral. A partir disso, foram identificadas questôes relevantes dentro do tema da formação e também os participantes da amostra para compor o grupo focal. Foram utilizados os seguintes critérios de inclusão de participantes: que fosse indicado pelo gestor local como Apoiador Matricial e que se reconhecesse como tal (autodeclaração de que trabalha com a metodologia de apoio). Foram utilizados como critérios de exclusão: a autodeclaração de que não realiza apoio, a indisponibilidade para responder o questionário por motivo de férias ou afastamento e a recusa em participar da pesquisa.

Procedendo dessa forma, emergiu como nosso universo de pesquisa um total de 277 profissionais que desenvolvem Apoio Matricial, distribuídos entre 81 serviços, de diferentes pontos da rede assistencial de Campinas. Dos 277 apoiadores que se adequavam aos critérios de seleção descritos acima, 206 responderam ao questionário, no período de abril de 2013 a outubro de 2013. Essa amostra corresponde a $74 \%$ do total do universo identificado.

Foi respeitada a distribuição pelos cinco distritos do SUS/Campinas, garantindo que fossem entrevistados profissionais dos cinco distritos de saúde 
do município, e também houve a preocupação em abranger diferentes serviços.

Os 71 faltantes $(26 \%)$ correspondem a trabalhadores que não conseguiram disponibilizar horários para a aplicação do questionário. Os dois serviços hospitalares em que havia especialistas que desenvolvem Apoio Matricial não concederam espaço na agenda para a aplicação dos questionários. Assim, representam o maior ônus para a pesquisa, por se tratar de arranjos pouco comuns e que poderiam apresentar respostas diferenciadas.

O questionário utilizado era composto por questôes fechadas e continha: itens de identificação do respondente; temas referentes à formação em Saúde Coletiva, tanto na graduação como na pós-graduação; oportunidades de formação em Apoio Matricial oferecidas pela gestão municipal; e avaliação sobre a importância de diferentes processos formativos. O questionário foi validado em um pré-teste.

$\mathrm{Na}$ segunda etapa da pesquisa, que corresponde à utilização do método qualitativo para o aprofundamento das questôes, elegemos a técnica do grupo focal (TANAKA; MELO, 2004; GONDIM, 2003; MINAYO, 2010). Para a seleção da amostra que participaria do grupo focal, foram consideradas as respostas obtidas com a aplicação do questionário, que ajudaram a compor o critério de inclusão. $\mathrm{O}$ critério formulado baseou-se na ideia de respeitar a proporção de apoiadores por serviço de origem e de agregar representantes dos arranjos mais frequentes de Apoio Matricial.

Os serviços com maior número de apoiadores encontrados foram os Centros de Saúde (CS), com 75 apoiadores (36\%), e os Centros de Atenção Psicossocial (CAPS), com 51 apoiadores (25\%). Além desses, foram identificadas atividades de apoio originadas a partir dos Centros de Referência de algumas especialidades, como reabilitação, Aids, e a partir de especialistas ligados a policlínicas. Optou-se por convidar alguns desses profissionais e a equipe do NASF, por ser a única do município. Assim, foram convidados a participar dos grupos focais vinte e cinco profissionais do Apoio Matricial, sendo 8 trabalhadores dos CS, 4 dos CAPS, 5 do Centro de Referência em Reabilitação, 6 pessoas do NASF e 2 especialistas ligados à Policlínica. Do total de profissionais convidados, 13 compareceram para o grupo focal.

Em nossa pesquisa, a análise dos dados quantitativos obtidos com os questionários iniciou-se com a tabulação das respostas, seguida da análise descritiva dos dados, realizada a partir do estudo das frequências absolutas e 
relativas das respostas decompostas em categorias. Os dados reunidos foram sumarizados em tabelas e originaram gráficos com as distribuições.

O material produzido por meio do grupo focal foi analisado com o auxílio da construção de narrativas, tal como proposto por Onocko-Campos e Furtado (2008) a partir do estudo das obras de Ricoeur, para quem as narrativas são consideradas construções de histórias sobre o agir humano, isto é, a composição de um enredo que dá sentido e coerência aos acontecimentos. Após esse movimento analítico do material produzido por cada um dos instrumentos e de sua contextualização, foi realizada a integração dos métodos, representados pelos instrumentos.

Em todas as etapas da pesquisa foram cumpridos os requisitos da Resolução CNS no 466/12 e suas complementares, que dispõem sobre as normas para realização de pesquisa com seres humanos. O projeto foi aprovado pelo Comitê de Ética e Pesquisa (CEP) da Faculdade de Ciências Médicas da Universidade Estadual de Campinas (Unicamp) (parecer 196.809 de 18/01/2013) e pelo Centro de Educação dos Trabalhadores da Saúde de Campinas, antes que fosse iniciada a pesquisa. Todos os participantes assinaram o TCLE.

\section{Resultados e discussão}

\section{Caracterização dos processos de formação durante a trajetória profissional Graduação}

Todos os entrevistados possuíam ensino superior completo. Isso porque o critério de seleção estipulado visava à identificação dos profissionais de Apoio Matricial e esses, via de regra, tinham ensino superior em alguma área ligada à saúde.

No que se refere à graduação, $59 \%$ dos profissionais estavam formados havia dez anos ou mais, ao passo que $47 \%$ deles referiram menos tempo de formados (entre 0 e 9 anos). Durante esse período de sua trajetória profissional, 157 entrevistados (76\%) tiveram alguma aproximação com a temática da Saúde Coletiva.

O fato de a maioria relatar que teve alguma aproximação com a Saúde Coletiva durante a graduação condiz com o processo de mudanças curriculares estudados por Carvalho e Ceccim (2012), mediante a aprovação das Diretrizes Curriculares Nacionais para os cursos de Ensino Superior, que adotam o SUS como eixo orientador. De acordo com Braid, Machado e Aranha (2012), foi a partir de 1996 que o tema da interdisciplinaridade nos cursos de graduação 
na área da saúde começou a ser discutido no âmbito federal pelo Ministério da

Educação e foi introduzido por meio da Lei de Diretrizes e Bases da Educação (LDB - 9394/1996). Originaram-se então os Parâmetros Curriculares Nacionais (PCN) para o Ensino Básico e as Diretrizes Curriculares Nacionais para os cursos de Ensino Superior, aprovadas entre 2001 e 2004, que estimularam as mudanças curriculares.

Este período de reformulações coincide com o tempo de formação dos nossos participantes, sugerindo que esses profissionais já cursaram a graduação dentro desses novos parâmetros e que existe uma chance de que o início das discussões sobre a interdisciplinaridade e sobre o SUS tenha provocado diálogos com os temas da Saúde Coletiva.

Durante o grupo focal, os participantes relataram que seu curso de graduação apresentava o modelo tradicional - disciplinar e fragmentado, com pedagogia centrada na transmissão de saberes verticalizada, centrada no professor e desvinculada da realidade. Tal modelo é bastante citado e criticado por Almeida Filho (2010), Passamai et al. (2012), Nuto et al. (2006) e Souza (2001).

Como lembram Carvalho e Ceccim (2012) e Braid, Machado e Aranha (2012), esse modelo não se preocupa em estabelecer relação com o SUS. Começou a ser revisto formalmente a partir de 1996, quando foi desencadeado o processo de reformulação das Diretrizes Curriculares Nacionais, e desembocou em projetos como o Pró-saúde (Programa Nacional de Reorientação da Formação Profissional em Saúde), em 2005. O discurso dos trabalhadores, em alguma medida, aponta para esse processo de mudança que se tem tentado estabelecer para aproximar a universidade e o SUS.

Na graduação, alguns de nós vivenciamos uma pedagogia tradicional, no modelo biomédico, centrado na especialidade, sem o trabalho compartilhado. Mesmo nas especializaçôes e nas residências, prevalecia esse modelo. Mas outros de nós pudemos ter experiências diferentes, em cursos de graduação mais interdisciplinares voltados para o SUS e durante residência em saúde da família ou em especialização em saúde pública.

Vasconcelos (2013) pondera que na universidade brasileira há um movimento de busca de novas formas de ensino, que vêm experimentando e difundindo uma reorientação da aprendizagem. Nesse processo, para além das mudanças curriculares, criou-se um conjunto de estratégias pouco explícitas que vêm conseguindo redirecionar o ensino. Segundo o autor, para um conjunto considerável 
de estudantes comprometidos com a transformação social, estruturou-se um currículo informal que critica o modelo dominante e aponta novos rumos.

Isso parece ter acontecido na formação dos trabalhadores que participaram dos grupos, chamando atenção para a contribuição dessa formação com cunho social e político para o engajamento no trabalho em saúde, que talvez seja um dos motivadores para que esses profissionais continuem a investir no apoio apesar das circunstâncias desfavoráveis.

O que consideramos realmente importante durante a graduação foram os momentos de formação informal, tais como os movimentos políticos, movimentos estudantis e os projetos de extensão. Depois disso, achamos que nossa escola foi o Centro de Saúde, a vivência na Atenção Básica.

Embora não tenhamos formalmente nos currículos dos cursos atividades estruturadas voltadas ao debate político ou à discussão sobre as políticas públicas em saúde, é interessante notar que os trabalhadores valorizam esse tipo de formação. Em alguma medida, eles chamam atenção não apenas para a necessidade de estudos sobre essa temática, como também para a importância de se utilizar a política como lente para análise crítica de nossos cursos de graduação.

Em cursos com maior disponibilidade de se incluir a discussão sobre política, haveria maiores chances de se produzir o "efeito Paideia" nos estudantes, indo na direção do que propõem Campos, Cunha e Figueiredo (2013) e contribuindo para a formação de apoiadores.

\section{Pós-graduação e outros processos de formação em serviço}

Quando se perguntou sobre os processos de formação, a primeira modalidade que veio à mente dos trabalhadores foi a graduação; em seguida, vieram os cursos formais de pós-graduação, lato e stricto sensu, como as especializações e as residências. Os processos de formação em serviço, tais como os espaços de supervisão ou de educação permanente, não foram lembrados de imediato pelos participantes desta pesquisa. Contudo, ao longo do estudo, principalmente durante o grupo focal, exemplos de formação em serviço apareceram e foram valorizados enquanto espaços em que se pudesse discutir a prática.

Dos participantes, 182 profissionais (88\%) afirmaram ter pós-graduação, lato ou stricto sensu. A busca dos profissionais pela pós-graduação ocorreu por iniciativa própria, ou seja, não se deu por estímulo ou pressão da instituição 
empregadora. Os cursos de pós-graduação realizados pelos entrevistados podem ser divididos entre: cursos em Saúde Coletiva, que foram escolhidos por 101 profissionais (29\%) e apresentam maiores chances de contemplar o tema do Apoio Matricial; e cursos voltados para a própria especialidade, que figuram como preferência majoritária entre os profissionais, já que 24 (69\%) relataram ter participado desse tipo de formação. Os cursos voltados para as especialidades comumente não abordam o tema do Apoio Matricial. Eles se aproximam, em alguma medida, do que Mancia, Cabral e Koerich (2004) definem como educação continuada.

A maioria dos profissionais (170 pessoas; $83 \%$ ) não recebeu nenhum tipo de formação com o foco no papel do Apoio Matricial por iniciativa da Secretaria Municipal de Saúde. É importante destacar que a questão contida no instrumento de nossa pesquisa indagava apenas sobre formação voltada para a temática do apoio, não contemplando outros tipos de oferta do SUS/Campinas. Ainda assim, dado o elevado número de profissionais (206) que afirmam utilizar o Apoio Matricial como metodologia de trabalho, seria recomendável que o município investisse em processos de formação nessa área.

Embora estejamos relatando aqui apenas a experiência de Campinas, vale lembrar que é possível que a mesma lacuna em processos de formação que contemplem o tema do apoio ocorra em outros municípios brasileiros, como sugerem Ballarin, Blanes e Ferigato (2012) que verificaram formação deficiente e falta de experiência como aspectos que têm prejudicado a implantação do Apoio Matricial e dos NASF.

No grupo focal, a única exceção que apareceu no que se refere a cursos oferecidos pela secretaria municipal, relacionados ao Apoio Matricial, foi uma capacitação voltada para os profissionais da atenção básica. Trata-se de um curso introdutório que ocorreu durante a implantação do Programa Paideia (CAMPINAS, 2001; CAMPINAS, 2003) e esteve ligado à divulgação de conceitos relevantes para a reestruturação prevista pelo programa, o que incluía a criação de equipes de Apoio Matricial.

Durante a capacitação, o curso introdutório da época do Paideia, lá entre 2001 e 2003, o foco era a atenção básica, mas o tema do Apoio Matricial chegou a ser discutido. Estranhamos que ninguém das especialidades tenha sido convidado, tivemos que batalhar por vagas... Lamentamos que não tenha tido continuidade, pois muita gente que teve esse curso já saiu, gente nova chegou e o curso ficou lá no passado. 
Após essa capacitação, houve apenas algumas iniciativas pontuais de formação que incluíssem o apoio, desenvolvidas mediante o investimento das universidades, especialmente do Departamento de Saúde Coletiva da Unicamp, sob o formato de pesquisa-intervenção (FURLAN, 2012; FIGUEIREDO, 2012).

Essa proximidade com a Unicamp, importante polo de produção teórica sobre o Apoio Matricial, combinada com o interesse dos profissionais em buscar informaçōes, pode ter favorecido aquisição de conhecimento sobre o tema, já que 108 profissionais (53\%) afirmaram conhecer documentos oficiais ou textos (teoria) sobre o Apoio. Esses números sugerem que houve um processo de "autoformação" dos apoiadores.

Embora essa "autoformação" ajude na assimilação de aspectos conceituais e técnicos, é preciso que ela seja complementada a partir da proposição de espaços reflexivos, que favoreçam a articulação da teoria com a prática, a partir das discussões sobre o cotidiano de trabalho. Esse seria um caminho para uma formação mais humanística, como propõe Oury (1991).

Por sua vez, a pesquisa revelou que a Secretaria Municipal de Saúde parece não priorizar a construção de tais espaços de reflexão, uma vez que 156 profissionais (76\%) relataram ausência de processos de formação sob o formato de apoio institucional ou de supervisão para desenvolver Apoio matricial. Esse tipo de recurso, utilizado por Figueiredo (2012) e descrito em Campos, Cunha e Figueiredo (2013), contribui para aumentar a capacidade de análise e de intervenção dos coletivos, e poderia ser ofertado para os apoiadores.

Em contrapartida, os profissionais identificaram outros arranjos apoiados pela Secretaria e que puderam ser aproveitados para disseminar o tema do trabalho na lógica do Apoio Matricial, embora esse não fosse seu propósito inicial. Trata-se dos espaços de planejamento e de avaliação, das reuniôes de território, voltadas a todos os profissionais de um distrito, incluindo ainda os fóruns de Saúde Mental.

Consideramos que os espaços de acompanhamento, de avaliação, de planejamento, de reuniōes de eixo, e os fóruns de Saúde Mental também são relevantes para a discussão do nosso trabalho, quando o tema do Apoio Matricial aparece. Só que achamos que eles deveriam ser qualificados, porque o tema aparece, mas por algum motivo ele é deixado de lado.

A análise dos itens referentes à formação em serviço ou à pós-graduação indica que houve pouco investimento da gestão, mas que os profissionais buscaram, de forma independente, cursos e outras formas de aquisição de conhecimento 
e de reflexão sobre a prática para suprir essa lacuna. Contudo, tendo em vista

a complexidade do tema e recomendação dessa metodologia de trabalho por parte do Ministério da Saúde, mediante a criação dos NASF, é importante que os municípios, aliados às instituições de ensino, passem a investir mais na capacitação dos profissionais. A formação dos apoiadores não pode depender somente das iniciativas dos próprios trabalhadores.

\section{Avaliação dos trabalhadores sobre processos formativos para o apoio}

Embora a Secretaria Municipal de Saúde não invista de modo contínuo em educação permanente, seja em cursos esporádicos ou na formação em serviço, os profissionais parecem atribuir importância a esse tipo de formação. Todas as modalidades de formação apresentadas foram avaliadas como "importante" ou "muito importante". Aparentemente, os profissionais valorizam principalmente os espaços de reflexão da prática (formação em serviço), já que a educação permanente e a supervisão ou apoio receberam a elevada quantidade de menções "muito importante", conforme se observa no gráfico abaixo.

Gráfico 1. Distribuição dos profissionais sobre como avaliam os diferentes tipos de formação para o Apoio Matricial; Secretaria Municipal de Saúde de Campinas, 2013

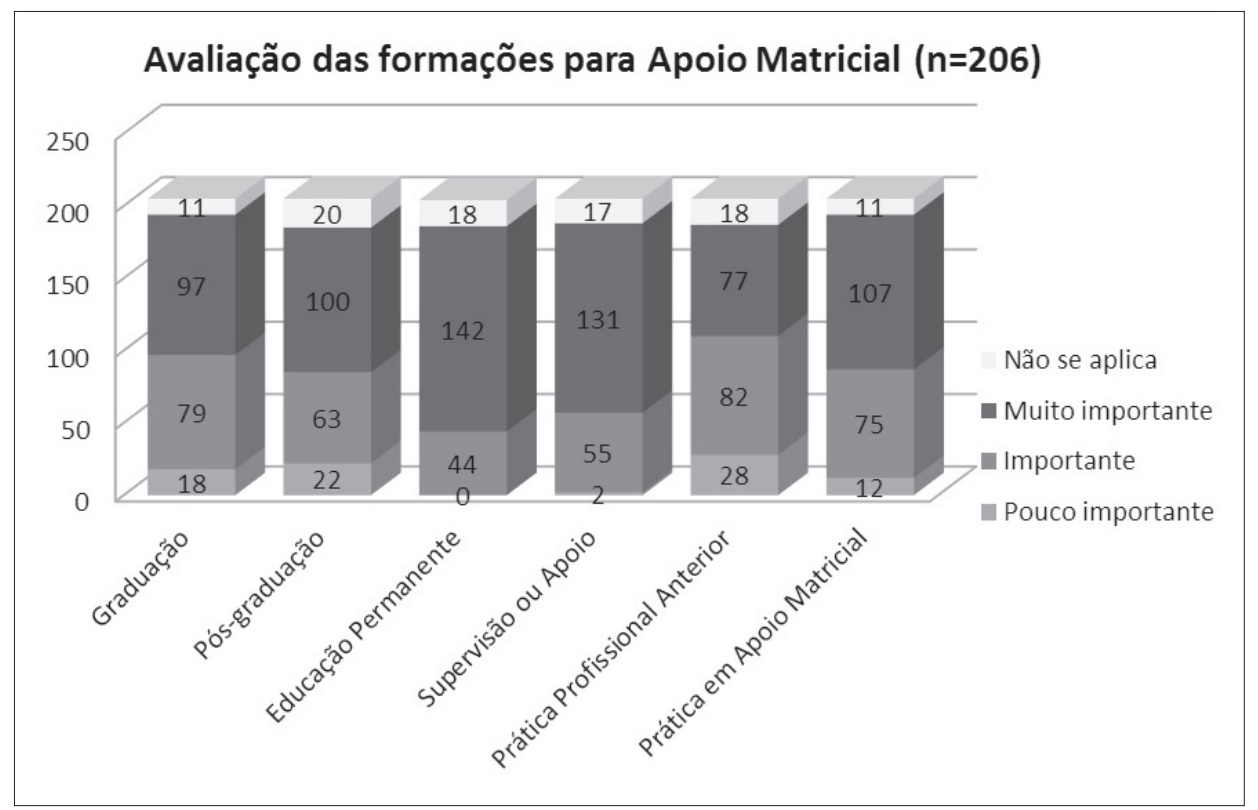


Nota-se também a valorização da vivência, nomeada nesta pesquisa como prática profissional em Apoio Matricial. Ela estaria ligada ao "aprender fazendo", descrito por Domitti (2006) como o principal dispositivo de formação para os profissionais que iniciaram o Apoio Matricial no município:

Começamos a fazer o Apoio Matricial a partir da nossa boa vontade, com o entendimento que tínhamos do que seria isso.

O dispositivo da educação permanente, bastante valorizado no levantamento quantitativo, não repercutiu da mesma forma no grupo focal. Nele, os trabalhadores reforçaram os espaços de discussão sobre a prática, indiscriminadamente, sem especificar se estavam se referindo aos termos "Educação Permanente", "Supervisão" ou "Apoio para o Apoio". De qualquer modo, pode-se inferir que todos esses recursos formativos estão contidos no que ficou denominado, no discurso dos participantes, como "momento de discussão sobre a prática".

Alguns de nós temos momentos de discussão sobre a prática no cotidiano do trabalho, e isso ajuda a dar mais segurança para nosso trabalho no Apoio Matricial, porque conseguimos compartilhar experiências, mas cada um se organiza de um jeito e não é uma coisa que tem, assim, uma frequência previsível, não é sistemático. Também gostaríamos de poder trazer pessoas externas para esses encontros, mas não conseguimos e sentimos falta disso.

Esses espaços, conforme mencionado no trecho acima, parecem depender majoritariamente da iniciativa dos próprios trabalhadores, chamando atenção para sua capacidade de auto-organização. Contudo, fica para eles a impressão de que faltou algo ou alguém para validar ou enriquecer esses processos. Talvez se trate do mesmo elemento relatado na pesquisa de Capazzolo et al. (2014), na qual os alunos demonstraram dúvida em relação à validade do conhecimento produzido na prática, com pouca explicitação de elementos teóricos e conduzido sem a mediação de figuras externas, investidas de suposto saber.

Por fim, é preciso enfatizar que toda a avaliação dos profissionais sobre os processos formativos esteve permeada por um eixo central: a crítica quanto à insuficiência de investimento em processos de formação. Em sua análise, os trabalhadores chamam atenção para a relação entre gestão e formação de pessoas e identificam nela o motivo da escassez de investimentos:

Ele [o Apoio Matricial] ainda é muito conjuntural e talvez por isso não se invista muito na nossa formação.

Como no momento não parece que o apoio seja o modelo no nosso município, nós não tivemos a formação teórica, não fizemos nenhum curso, nenhuma capacitação. 
A análise dos participantes demonstra maturidade e remete à dificuldade de consolidação do apoio enquanto metodologia de trabalho no município e à necessidade de se formar pessoas e de mudar serviços e diretrizes, tudo junto e ao mesmo tempo, como propõe Campos (2000). Teríamos aí uma boa advertência para outros municípios brasileiros que pretendem implantar o Apoio Matricial.

\section{Indicações dos trabalhadores sobre a formação desejável para o Apoio Matricial}

Os profissionais divergem quanto à necessidade de uma formação específica para o Apoio Matricial, pois alguns acreditam que o trabalho interdisciplinar já deveria fazer parte de todas as graduaçôes na área da saúde.

Além disso, alguns deles foram capturados pelo mito da formação, acreditando que se todos tivessem conhecimentos sobre o apoio, as dificuldades se amenizariam. No entanto, outros trouxeram a perspectiva de que a formação, por si só, não seria capaz de dar conta de tudo isso, pois se trataria de dificuldade de gestão e de modelo. Quando essa dimensão foi levantada, o restante do grupo pareceu concordar.

Como já mencionado, Campos $(1990 ; 1999)$ faz justamente a discussão de que qualquer processo de formação para os atores da área da saúde só trará resultados se estiver associada a mudanças políticas, enfatizando que cursos e capacitações isolados não bastam. Essa percepção parece ter sido construída também no grupo de trabalhadores.

Às vezes achamos que, se todo mundo tivesse conhecimento sobre o apoio, as coisas melhorariam, mas no fundo a gente sabe que isso só vai acontecer mesmo se for definido que o Apoio Matricial é O MODELO que a gente vai fazer. Mas, o que parece aqui pra gente, é que o Apoio Matricial não está definido como um modelo valorizado pela gestão, não.

Quanto à proposta para um modelo de formação para o Apoio Matricial, consideram fundamental a articulação com a prática e a parceria com a gestão para poder promover mudanças. Trata-se, aparentemente, de garantir subsídios para a formulação e ressignificação da práxis, na medida em que propõem um aprendizado centrado na vivência (FREIRE, 2011). De alguma maneira, coincidem com a posição de Campos, Cunha e Figueiredo (2013) de aliar a dimensão pedagógica com a política e subjetividade para a coprodução dos sujeitos. 
Nós achamos que a formação é importante, mas ela deve ir para além da técnica e dos conhecimentos sobre política e rede. Ela deve se centrar na vivência. É importante ter uma noção sobre o conceito de Apoio Matricial, mas articulado com a prática, pois muitas vezes sabe-se o que é Apoio Matricial, mas não se sabe como fazer.

As habilidades que os participantes mencionaram como desejáveis a um apoiador, e que os trabalhadores gostariam que fossem desenvolvidas a partir dos processos formativos, apresentam relação com o que Gonzalez et al. (2012) chamam de "aprender a lidar com o outro" e com a proposta de Oury (1991) sobre ajudar os profissionais a se tornarem "sensíveis ao contexto, à polifonia dos discursos e às manifestações paradoxais", o que por sua vez estaria ligado ao desenvolvimento da personalidade, incluindo a dimensão ética inerente ao estar com o outro.

Apoio requer que o profissional saiba ouvir e que esteja aberto para o encontro. É importante que o Apoiador saiba trabalhar com grupos e lidar com as equipes a partir de uma posição mais compartilhada.

Dentre os temas teóricos, os que despertam maior interesse dos trabalhadores, devido à sua relevância para o papel do apoiador, são: trabalho em rede, modelos de gestão e de atenção, comunicação, manejo de grupos e estratégias pedagógicas. Além disso, os trabalhadores chamam atenção para a dificuldade na "manutenção do matriciamento", integrados a todas as fases do processo de cuidado, salientando que isso deveria entrar no rol de assuntos dos processos de formação. Gostariam que esse tema versasse sobre como conseguir prosseguir com um trabalho efetivo, passado o momento inicial de pactuação sobre a agenda com a equipe apoiada.

Essa manutenção, segundo os próprios trabalhadores, estaria relacionada à capacidade de escuta dos apoiadores e com sua abertura a mudanças, no sentido de acolher o que as equipes estão demandando.

Alguns de nós achamos que a formação deveria abordar a dúvida que temos sobre como desenvolver a manutenção do matriciamento, pois o "como iniciar" a gente até que discutiu bastante, mas o movimento e a mudança são importantes no Apoio Matricial.

A formação indicada pelos trabalhadores também parece buscar outra forma de se relacionar com a teoria, diferente da passividade presente no modelo que baseou sua graduação. Eles anseiam por uma estreita relação entre a teoria e a prática, a partir da construção de um saber próximo do fazer; desejam uma aprendizagem no sentido nobre do termo, como diria Oury (1991), em que 
as ferramentas conceituais são apresentadas para poder ajudar a selecionar no cotidiano a matéria-prima para o trabalho.

A proposta de articulação entre teoria e prática também está contida na racionalidade da práxis, apresentada por Campos (2011), que inclui a autonomia relativa dos agentes na mediação entre conhecimento e prática.

$\mathrm{Na}$ medida em que nomeiam a importância de combinar a formação de cada especialidade com saberes interdisciplinares, que seriam úteis para o trabalho na Saúde Coletiva, os trabalhadores concordam que é preciso considerar a perspectiva de campo e o núcleo de saberes (CAMPOS, 2000a; CAMPOS, 2007).

\footnotetext{
Além da formação básica de cada profissional, é preciso conhecer um pouco sobre o SUS, sobre Saúde Coletiva, sobre o modelo de atenção e de gestão e também sobre a organização da rede de serviços de saúde.

Em nossa opinião, o componente teórico não deveria ser seguido muito fielmente, pois às vezes ser muito puritano atrapalha o espaço de construção das açôes, já que a teoria nem sempre casa com a realidade.

$\mathrm{Na}$ verdade, achamos mesmo que tem alguma coisa aí nessa comunicação entre a teoria e a prática que não acontece não. Precisamos aproximar a relação, mas vemos que nem sempre é fácil dialogar.
}

\section{Conclusão}

A escolha pelo tema da formação para os profissionais do Apoio Matricial mostrou-se justificada enquanto estratégia para o fortalecimento da proposta do NASF, já em voga em todo o país. Ainda que esta pesquisa tenha se centrado em um município apenas, foi possível notar aspectos que podem ser úteis também em outros contextos onde se perceba dificuldades para avançar na política de formação de pessoal, seja para o apoio, ou em geral.

Durante todo o estudo, os participantes destacaram sua insatisfação com a ausência de formação sistemática para o apoio e sugeriram que a secretaria municipal ofertasse capacitações e contribuições que enriquecessem os espaços de discussão criados pelos próprios profissionais. Eles atribuem a ausência de formação à falta de investimentos da secretaria nas práticas de Apoio Matricial e chegam a ponderar que os processos de formação devem estar sempre vinculados a uma diretriz política.

A valorização da formação não deve ser utilizada como uma justificativa para precariedade de aspectos estruturais sobre os quais os profissionais têm pouca 
governabilidade, como aqueles relacionados à gestão de recursos físicos, humanos e à organização do trabalho. Os trabalhadores demonstraram perceber que esses aspectos são a pedra angular do apoio e que a formação seria um componente para qualificá-lo, mas que não garante seu funcionamento.

Encontramos entre os participantes uma expectativa de que todos fossem formados para o apoio, inclusive as equipes de referência. Seria uma formação que valorizasse os processos que, na percepção deles, baseiam-se na discussão sobre sua realidade e que articulasse teoria e prática.

Ademais, os apoiadores esperam que a formação contribua para melhorar a relação com as equipes e que os ajude a encontrar um caminho para o que eles chamaram de "manutenção do apoio".

A crítica dos trabalhadores à escassez de formação para o Apoio Matricial e sua expectativa em poder vivenciar processos formativos, centrados na reflexão sobre a prática e no desenvolvimento da autonomia, dão pistas sobre alguns caminhos a se trilhar.

Em primeiro lugar, fica claro que os municípios que desejam iniciar ou avançar na implantação do Apoio Matricial e dos NASF precisam estar atentos à política de formação de pessoal. Em segundo lugar, o modelo pedagógico a ser utilizado precisa superar o tradicional e avançar para propostas pautadas em metodologias ativas e em aprendizagem significativa, aproximando-se da pedagogia de Paulo Freire. Em suma, trata-se de aliar conhecimento, política e subjetividade; na mesma linha em que o próprio apoio pretende trabalhar. ${ }^{1}$

\section{Referências}

ALMEIDA FILHO, N. Reconhecer Flexner: inquérito sobre produção de mitos na educação médica no Brasil contemporâneo. Cadernos de Saúde Pública, v. 26 n. 12, p. 2234-2249, 2010. BALLARIN, M.L.G.S.; BLANES, L.S.; FERIGATO, S.H. Apoio Matricial: um estudo sobre a perspectiva de profissionais da saúde mental. Interface - Comunicação, Saúde, Educação, v. 16, n. 42, p. 767-778, 2012.

BRAID, L.M.C.; MACHADO, M.F.A.S.; ARANHA, A.C. Estado da arte das pesquisas sobre currículo em cursos de formação de profissionais da área da saúde: um levantamento a partir de artigos publicados entre 2005 e 2011. Interface - Comunicação, Saúde, Educação, v. 16, n. 42, p. 679-92, 2012. 
BRASIL. Ministério da Saúde. Política Nacional de Educação Permanente em Saúde. Brasília:

Ministério da Saúde; 2009.

. Portaria no 154, de 24 de janeiro de 2008. Cria os Núcleos de Apoio à Saúde da

Família - NASF. Diário Oficial da República Federativa do Brasil. Brasília: Gabinete do Ministro. Seção 1, p. 47-50, 2008.

. Departamento de Atenção Básica. Relatório de cobertura da Saúde da Família

2015. Disponível em: <http://dab.saude.gov.br/dab/historico_cobertura_sf/historico_ cobertura_sf_relatorio.php $>$. Acesso em: 22 fev. 2016).

CAMPINAS. Colegiado de Gestão da Saúde. As Diretrizes da Secretaria Municipal de Saúde - Gestão 2001 - 2004. Projeto Paideia de Saúde da Família. Campinas/SP: Secretaria Municipal de Saúde, 2001.

- Programa Paidéia. Saúde da Família: 2001-2004: Campinas. Campinas/SP: Secretaria Municipal de Saúde, 2003.

CAMPOS, G.W.S.; CUNHA, G.T.; FIGUEIREDO, M.D. Práxis e Formação Paideia: apoio e cogestão em saúde. São Paulo: Hucitec, 2013.

CAMPOS, G.W.S.; DOMITTI, A.C. Apoio Matricial e Equipe de Referência: uma metodologia para gestão do trabalho interdisciplinar em saúde. Cadernos de Saúde Pública, v. 23, n. 2, p. 399-407, 2007.

CAMPOS, G.W.S. A mediação entre conhecimento e práticas sociais: a racionalidade da tecnologia leve, da práxis e da arte. Ciência \& Saúde Coletiva, v. 16, n. 7, p. 3033-3340, 2011.

. Campo e núcleo de conhecimentos e de responsabilidade. In: Memórias

de um médico sanitarista que virou professor enquanto escrevia sobre. São Paulo: Hucitec; 2007. p. 117-118.

Equipes de Referência e apoio especializado matricial: um ensaio sobre a reorganização do trabalho em saúde. Ciência \& Saúde Coletiva, v. 4, n. 2, p. 393-403, 1999.

. Reflexões sobre uma proposta de gestão. Rev. Adm. Públ. Rio de Janeiro, v. 24, n. 4, p. 46-52, 1990.

- Um método para análise e cogestão de coletivos: a constituição do sujeito, a produção de valor de uso e a democracia em instituições: o método da Roda. São Paulo: Hucitec, 2000. - Saúde pública e saúde coletiva: campo e núcleo de saberes e práticas. Ciência \& Saúde Coletiva, v. 5, n. 2, p. 219-230, 2000.

CAPOZZOLO, A.A. et al. Narrativas na formação comum de profissionais de saúde. Trab. educ. saúde, Rio de Janeiro, v. 12, n. 2, p. 443-456, 2014.

CARVALHO, Y.M.; CECCIM, R.B. Formação e educação em saúde: aprendizados com a saúde coletiva. In: CAMPOS, G.W.S et al. (Org.). Tratado de Saúde Coletiva. 2. Ed. São Paulo: Hucitec, 2012. p. 137-170. 
CRESWELL, J.W. Projeto de pesquisa: métodos qualitativo, quantitativo e misto. 2. Ed. Porto Alegre: Artmed, 2007.

. Research Design: qualitative, quantitative and mixed methods approaches. 3. Ed. United States of America: SAGE publications, 2009.

CUNHA, G.T.; CAMPOS, G.W.S. Apoio Matricial e Atenção Primária em Saúde. Saúde e Sociedade, v. 20, n. 4, p. 961-970, 2011.

- Método Paideia para cogestão de coletivos organizados para o trabalho. Revista ORG \& DEMO, v. 11, n. 1, p. 31-46, 2010.

CUNHA, G.T.; DANTAS, D.V. Uma contribuição para a cogestão da clínica: grupos Balint-Paideia. In: CAMPOS, G.W.S.; GUERRERO, A.V.P. (Org.). Manual de Práticas de Atenção Básica: Saúde Ampliada e Compartilhada. São Paulo: Hucitec, 2010. p. 34-60.

CUNHA, G.T. Balint-Paideia: uma contribuição para a cogestão e a clínica ampliada na Atenção Básica. 2009. 254 f. Tese (Doutorado em Saúde Coletiva) - Faculdade de Ciências Médicas, Universidade Estadual de Campinas. 2009.

DOMITTI, A.C.P. Um possível diálogo com a teoria a partir das práticas de Apoio Especializado Matricial na Atenção Básica de Saúde. 2006. 87 f. Tese (Doutorado em Saúde Coletiva) Faculdade de Ciências Médicas, Universidade Estadual de Campinas, Campinas. 2006.

FIGUEIREDO, M.D. A construção de práticas ampliadas e compartilhadas em saúde: apoio Paidéia e formação. 2012. 341 f. Tese (Doutorado em Saúde Coletiva) - Faculdade de Ciências Médicas, Universidade Estadual de Campinas, Campinas. 2012.

FREIRE, P. Pedagogia da autonomia: saberes necessários à prática educativa. 43. ed. São Paulo: Paz e Terra, 2011.

FURLAN, P.G. Os grupos na atenção básica à saúde: uma hermenêutica da prática clínica e da formação profissional. 2012. 236 f. Tese (Doutorado em Saúde Coletiva) - Faculdade de Ciências Médicas, Universidade Estadual de Campinas, Campinas. 2012.

GONDIM, S.M.G. Grupos focais como técnica de investigação qualitativa: desafios metodológicos. Paideia, v. 12, n. 24, p. 149-116, 2003.

GONZÁLEZ, A.D. et al. Fenomenologia heideggeriana como referencial para estudos sobre formação em saúde. Interface - Comunicação, Saúde, Educação, v. 16, n. 42, p. 809-817, 2012.

MANCIA, J.R.; CABRAL, L.C.; KOERICH, M.S. Educação Permanente no contexto da enfermagem e na saúde. Rev. Bras. Enferm., Brasília (DF), v. 57, n. 5, p. 605-610, 2004. MINAYO, M.C.S. O Desafio do Conhecimento - Pesquisa Qualitativa em Saúde. 11. Ed. Rio de Janeiro: Hucitec, 2010.

NUTO, S.A.S. et al. O processo ensino-aprendizagem e suas consequências na relação professor-aluno-paciente. Ciência \& Saúde Coletiva, v. 11, n. 1, p. 89-96, 2006. 
OLIVEIRA, G.N. Apoio Matricial como tecnologia de gestão e articulação em rede. In:

CAMPOS, G.W.S.; GUERRERO, A.V.P. (Org.). Manual de Práticas de Atenção Básica: Saúde Ampliada e Compartilhada. São Paulo: Hucitec, 2010. p. 273-82.

ONOCKO-CAMPOS, R.; FURTADO, J.P. Narrativas: apontando alguns caminhos para sua utilização na pesquisa qualitativa em saúde. In: (Org.). Pesquisa avaliativa em saúde mental: desenho participativo e efeitos da narratividade. São Paulo: Aderaldo \& Rotschild Editores; 2008. p. 321-33.

OURY J. Itinerários de formação. Revue Pratique, v. 1, p. 42-50, 1991.

PASSAMAI, M.P.B. et al. Letramento funcional em saúde: reflexões e conceitos sobre seu impacto na interação entre usuários, profissionais e sistema de saúde. Interface Comunicação, Saúde, Educação, v. 16, n. 41, p. 301-314, 2012.

PEDUZZI, M. et al. Atividades educativas de trabalhadores na atenção primária: concepções de educação permanente e de educação continuada em saúde presentes no cotidiano de Unidades Básicas de Saúde em São Paulo. Interface - Comunicação, Saúde, Educação, v. 13, n. 30, p. 121-134, 2009.

SOUZA, A.N. Formação médica, racionalidade e experiência. Ciência \& Saúde Coletiva, v. 6, n. 1, p. 87-96, 2001.

TANAKA, O.Y.; MELO, C. Avaliação de Programas de Saúde do Adolescente: um modo de fazer. São Paulo: Editora USP, 2004.

VASCONCELOS, E.M. Educação popular e o movimento de transformação da formação universitária no campo da saúde. In: Educação popular na formação universitária. São Paulo: Hucitec; João Pessoa: Editora Universitária UFPB, 2013. p. 362-397.

\section{Nota}

${ }^{1}$ M.M. de Oliveira participou da concepção, formulação e desenvolvimento de todas as etapas do artigo. G.W.S Campos contribuiu com elementos de análise, interpretação e revisão do material apresentado. 


\title{
Abstract
}

\author{
Training for Matrix Support: professionals' \\ perception about training processes \\ The main objective of this article is to analyze the \\ professionals' perception about training processes \\ that will help them to perform matrix support. The \\ research was conducted in Campinas-SP, Brazil. Two \\ investigative movements were carried out: exploratory \\ (quantitative) phase with 206 professionals and \\ qualitative research, using the focal group technique, \\ with an intentional sample. The participants highlighted \\ their dissatisfaction with the absence of systematic \\ training for support and associated it with the scarce \\ investment that has been made in the Matrix Support \\ in the municipality. They realize that the training could \\ help them to improve the interdisciplinary work and \\ the care offered, provided that the pedagogical model \\ privileges the reflection on the practice.
}

> Keywords: formation and development; matrix support; health continuing education. 